\title{
artigo
}

Francelino, A.G.; Quinderé, P.H.D.; Rimes, T.S.; Andrade, A.T.; Costa, L.S.P.; Morais, S.S.F.

Compreensões de estudantes e professores de uma escola pública de ensino fundamental sobre uso de crack na adolescência

\section{Compreensões de estudantes e professores de uma escola pública de ensino fundamental sobre uso de crack na adolescência}

\author{
Public primary school students' and teachers' understanding of crack use in adolescence \\ Comprensión de estudiantes y profesores de una escuela primaria pública sobre el consumo de crack en la adolescencia
}

\begin{abstract}
RESUMO
Objetivou-se compreender as representações de alunos e professores sobre o consumo de crack na adolescência. Trata-se de pesquisa-ação, realizada em escola pública no município de Fortaleza-CE, com doze estudantes e sete professores, de junho a agosto de 2015. Para coleta de dados, realizamos grupos focais com os estudantes e entrevistas com os professores, utilizando a técnica de gravação. Para análise dos dados, utilizamos a análise interpretativa dos desenhos produzidos nos grupos focais com base no referencial teórico de Jean Piaget. Para analisar as falas dos alunos e dos professores realizamos a transcrição na íntegra e seguimos a fenomenologia hermenêutica de Paul Ricoeur. Os resultados identificaram contradição entre as falas dos participantes: por um lado, uma reflexão diferente do que é construído socialmente a respeito do usuário, e, por outro, um discurso atrelado ao que veem na mídia e ao que vivenciam junto aos familiares que fazem uso de crack de forma desorganizada. DESCRITORES: Adolescência; Crack; Educação.
\end{abstract}

\section{ABSTRACT}

We aimed to understand students' and teachers' representations of crack use in adolescence. Action research was carried out in a public school in the city of Fortaleza, Ceará, with twelve students and seven teachers from June to August 2015. Data were collected from focus groups held with students and interviews with teachers using the recording technique. For data analysis, we used the interpretative analysis of the drawings made in the focus groups based on the theoretical framework of Jean Piaget. In order to analyze students' and teachers' statements, we transcribed the material verbatim and applied Paul Ricoeur's hermeneutical phenomenology. The results identified a contradiction between the participants' statements: on the one hand, there is a different idea of what is socially constructed about the user, and, on the other, there is a discourse linked to what they see in the media and to what they experience with family members who use crack in a disorganized way.

DESCRIPTORS: Adolescence; Crack; Education.

\section{RESUMEN}

El objetivo fue comprender las representaciones de estudiantes y docentes sobre el consumo de crack en la adolescencia. Se trata de una investigación acción realizada en una escuela pública de la ciudad de Fortaleza, Ceará, con doce alumnos y siete profesores de junio a agosto de 2015. Para la recolección de datos, se realizaron grupos focales con alumnos y entrevistas con profesores utilizando la técnica de grabación. Para el análisis de datos, se utilizó el análisis interpretativo de los dibujos producidos en los grupos focales basados en el marco teórico de Jean Piaget. Para analizar los discursos de los alumnos y profesores, realizamos la transcripción íntegra y seguimos la fenomenología hermenéutica de Paul Ricoeur. Los resultados identificaron una contradicción entre las afirmaciones de los participantes: por un lado, un reflejo diferente de lo que se construye socialmente sobre el usuario y, por otro, un discurso vinculado a lo que ven en los medios y lo que viven con los familiares que usan crack de forma desorganizada. DESCRIPTORES: Adolescencia; Crack; Educación.

RECEBIDO EM: 29/10/2020 APROVADO EM: 24/12/2020

\section{Aglay Galvão Francelino}

Mestre em Saúde da Criança e do Adolescente pela Univerdade Estadual do Ceará, Especialista em Saúde do Idoso pela Universaidade Estadual do Ceará, Bacharel em Enfermagem pela Universidade de Fortaleza.

ORCID: 0000-0003-2626-0364 


\section{Paulo Henrique Dias Quinderé}

Psicólogo, Doutor em Saúde Coletiva, Prof. do curso de psicologia e do programa de pós graduação Mestrado Profissional em Psicologia e Políticas Públicas da Universidade Federal do Ceará - Campus Sobral.

ORCID: 0000-0002-8470-1909

\section{Thalita Soares Rimes}

Enfermeira. Mestre em saúde coletiva. Especialista em urgencia e emergência. Coordenadora do curso de enfermagem da faculdade vidal de limoeiro do norte.

ORCID: 0000-0002-1591-8522

\section{Aline Teles de Andrade}

Psicóloga, Especialista em Saude Mental pela Universidade Estadual do Ceará-UECE, Mestre em Saúde Coletiva pela Universidade Estadual do Ceará - UECE, Doutorando do Programa de Psicologia da Universidade Federal do Ceará - UFC.

ORCID: 0000-0002-6456-8282

\section{Lourdes Suelen Pontes Costa}

Mestre em Saúde Coletiva, Bacharel em Enfermagem pela Universidade Estadual do Ceará.

ORCID: 0000-0001-8589-0214

\section{Sônia Samara Fonseca de Morais}

Enfermeira. Doutora em Saúde Coletiva pela UECE. Enfermeira Assistencial do Hospital Leonardo da Vinc. ORCID: 0000-0002-0146-4611

\section{INTRODUÇÃO}

0 surgimento de novas drogas, em especial o crack, tem sido alvo de estudos pelo Brasil e pelo mundo. Tal fato provoca questionamentos quanto aos desfechos secundários inerentes aos usuários, à eficiência das políticas públicas para lidar com o assunto e à abordagem tradicional do proibicionismo, sobretudo para o público adolescente ${ }^{1}$.

A tendência para o aumento do uso de drogas entre os jovens pode ser compreendida pelas mudanças físicas, hormonais e sociais verificadas no período da adolescência ${ }^{2}$. De acordo com alguns autores ${ }^{3}$, os fatores de risco para o início do uso de drogas estão relacionados aos aspectos contextuais - a baixa condiçãao socioeconômica, a disponibilidade da droga, a carência de vínculo familiar, pouco envolvimento em atividades religiosas, baixa adesão às atividades escolares e influência dos amigos - bem como aos aspectos endógenos, ou seja, psicopatologias, baixa autoestima, falta de perspectiva de vida, interesse por novas sensações, inclusive busca pelo prazer e curiosidadét.

Em corroboração à ideia, Costa $^{5}$ et al. identificam que as situações capazes de atrair ou distanciar os adolescentes do uso de drogas estão relacionadas tanto aos fatores de influência como aos fatores protetores, entre eles: família, grupo social, escola, vida em área de risco e mídia.

Quanto ao panorama de uso de drogas ilícitas entre adolescentes, destaca-se o detectado no VI Levantamento Nacional sobre o uso de Drogas Psicotrópicas por estudantes do ensino fundamental e médio nas 27 capitais brasileiras ${ }^{6}$, isto é, $25,5 \%$ dos estudantes já fizeram uso de alguma droga ilícita, entre elas, inalantes, maconha, ansiolíticos, cocaína e anfetaminas. De acordo com o estudo realizado pelo Instituto de Pesquisa e Estratégia Econômica do Ceará (IPECE) ${ }^{7}$, estudantes do $9^{\circ}$ ano na cidade de Fortaleza consumiram crack dez ou mais vezes durante a vida, o que colocou a capital na $2^{\mathrm{a}}$ posição no ranking, comparativamente às demais capitais do país.

Nesse contexto, em face da possibilidade de os adolescentes constituírem um grupo vulnerável ao uso de drogas e terem contato com o crack, direta ou indiretamente, torna-se relevante pensar na corresponsabilização dos setores saúde e educação, no intuito de melhorar sua articulação para trabalhar essa temática nas escolas, nas unidades de saúde, nos lares, nas comunidades religiosas.

A aplicabilidade desta proposta de estudo com a linha de pesquisa voltada para a situação de saúde do adolescente está direcionada para a construção de um conhecimento sólido e reflexivo tanto para os serviços de saúde como para os espaços de ensino, uma vez que servirá como contribuição para trabalhar essa temática junto ao adolescente.

Assim sendo, questiona-se quais as representações que estes adolescentes têm sobre o uso de crack? Como os professores representam o uso dessas substâncias pelos adolescentes?

Diante do exposto, o presente artigo tem o objetivo de compreender as representações de estudantes e professores do ensino fundamental de Fortaleza acerca do uso de crack na adolescência.

\section{METODO}

Trata-se de uma pesquisa-ação com abordagem qualitativa, definida por Thiollent ${ }^{8}$ como um tipo de pesquisa social que para ser realizada requer intenso engajamento entre os participantes e os pesquisadores, a fim de investigar ou resolver determinado problema. Desse modo, procurou-se seguir o ciclo da pesquisa-ação e identificou-se como principais problemas: relatos de uso de drogas nas escolas por alunos do $6^{\circ}$ ano, carência de informação dos alunos sobre o crack e dificuldades enfrentadas pelos professores para trabalhar sobre a temática em 


\section{artigo}

Francelino, A.G.; Quinderé, P.H.D.; Rimes, T.S.; Andrade, A.T.; Costa, L.S.P.; Morais, S.S.F.;

Compreensões de estudantes e professores de uma escola pública de ensino fundamental sobre uso de crack na adolescência

sala de aula. Neste âmbito, citam-se a elaboração de uma cartilha educativa para abordar o assunto nas escolas e a educação em saúde durante os grupos focais como parte da etapa do estudo intitulada ação.

Como referido, o estudo se desenvolveu no município de Fortaleza, em uma escola localizada na Secretaria Regional VI. A escola selecionada conta com uma população estudantil de 1.000 alunos, 30 professores, 2 coordenadores pedagógicos, 1 diretor e 1 vice-diretora.

Fez-se a coleta de dados nos meses de junho a agosto de 2015, com amostra de doze adolescentes na faixa etária de 10 a 13 anos, entre eles, cinco meninos e sete meninas. Ainda, foram entrevistados sete professores, entre eles, quatro mulheres e três homens.

Os fatores de inclusão foram alunos matriculados no $6^{\circ}$ ano e os fatores de exclusão foram os alunos que não estavam matriculados no $6^{\circ}$ ano. Para os professores utilizou-se como critério de inclusão os que estavam em planejamento pedagógico e como fator de exclusão os professores que estavam desenvolvendo atividades em sala de aula no dia da coleta de dados.

Como instrumento de coleta optou-se pela entrevista semiestruturada junto aos professores, e, para coleta de dados junto aos alunos, optou-se por dois grupos focais com 12 adolescentes.

A dimensão teórica seguida nessa fase de análise foi atribuída a Paul Ricoeur que se norteia pela hermenêutica fenomenológica, o qual descreve como conduzir a análise de um texto. A hermenêutica pode ser utilizada como referencial para interpretar e analisar qualquer tipo de texto. Paul Ricouer considera a hermenêutica como um sistema de interpretação utilizado como método para compreender conteúdos e significados manifestos ou ocultos. Nesta pesquisa o objeto de interpretação será o texto, produzido através das transcrições das entrevistas ${ }^{9}$

Além dos debates, buscou-se criar outras estratégias para estimular as discussões entre os adolescentes. Entre elas, sobressaiu a elaboração de desenhos pelos próprios participantes para representar tema em discussão.

Nesse sentido, tentou-se interpretar as construções simbólicas (desenhos) com base nos pressupostos teóricos de Piaget.

As questôes tanto da entrevista como dos grupos focais, juntamente com a construção dos desenhos pelos estudantes, procuraram estimular a discussão sobre o uso de crack na adolescência e suas repercussões.

Desta forma, destacou-se o seguinte tema: "Matar aula é igual a crack, você experimenta uma vez e nunca mais para": compreensões sobre o uso na adolescência - as discussões fundamentaram-se na estigmatização acerca do usuário de crack, identificados pelo padrão de uso problemático - e os seguintes subtemas: crack como símbolo de autoafirmação e desafio e padrões de consumo e estigmatização.

Como exigido, o projeto foi submetido à Plataforma Brasil gerando Certificado de Apresentação de Apreciação Ética (CAAE) $n^{\circ} 44320015400005534$, sendo aprovado após análise do Comitê de Ética em Pesquisa da Universidade Estadual do Ceará (UECE) com parecer de $\mathrm{n}^{\circ}$ 1.115.302.

\section{RESULTADOS E DISCUSSÕES}

"Matar aula é igual crack, você experimenta uma vez e nunca mais para": compreensões sobre o uso na adolescência

Inicialmente, procurou-se compreender o fenômeno do uso de crack e quais representações são construídas acerca do usuário. Conforme se percebeu, tanto as repercussões positivas quanto as negativas surgiram com base nos discursos.

As representações positivas interpretadas nas falas e desenhos apontaram para a necessidade de afirmação, para o desafio pessoal atribuído ao crack, para o bem-estar e para as sensações agradáveis associadas ao uso.

Com base nas ideias de alguns autores ${ }^{10,11}$, o indivíduo é resultado de suas experiências, e assim, não há sentido em interpretar o desenho isoladamente, sem atentar para o contexto do indivíduo. A compreensão do desenho e a sua interpretação de forma isolada do contexto em que foi executado não tem qualquer sentido.

Notou-se contradição entre as falas. Como foi possível identificar, uma parte dos professores e dos estudantes trouxe uma representação diferente do que é construído socialmente a respeito do usuário, enquanto a outra apresentou um discurso atrelado ao exposto na mídia e às vivências junto aos familiares que fazem uso de crack de forma desorganizada.

\section{Crack como símbolo de autoafirmação e desafio}

Necessariamente, o consumo do crack impõe riscos e desafios que acabam sendo atrativos aos adolescentes. No desenho, a ideia do usuário de crack foi retratada pela imagem de um homem que pode representar alguém do seu próprio convívio - um amigo, um familiar ou outra pessoa da sua comunidade ou da sua escola.
Desenho 1: Elaborado pelos adolescentes estudantes, no primeiro grupo focal. Fortaleza-CE 2015

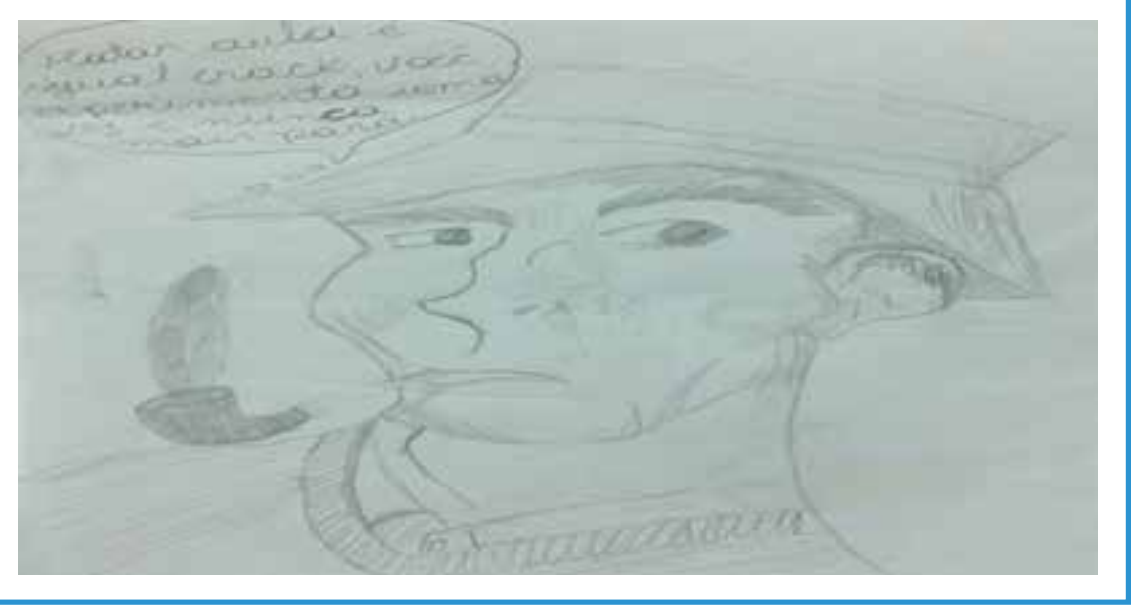


Diante desse contexto, consoante o simbolismo presente na imagem permite compreender, os adolescentes também sinalizam que sua ideia acerca do crack vai além dos efeitos físicos e químicos ocasionados pela droga. No entanto, também associam a ideia segundo a qual o crack é tão desafiador quanto matar aula. Como deixam subentender, esses eventos são prazerosos e para vivenciá-los é preciso ter coragem para burlar as normas construídas socialmente.

De acordo com Quinderé ${ }^{12}$, a relação do homem com a droga se expressa na construção de uma experiência que pode se tornar positiva em determinado momento, mas pode vir a ser negativa em outro momento da vida dos indivíduos.

Essa substância é vista ao mesmo tempo como sinônimo de destruição e desorganização e também símbolo de desafio e de curiosidade, alimentada até mesmo pela propaganda que tenta denegrir a imagem de quem usa, no intuito de afastar o jovem do "mundo das drogas". Esta iniciativa, no entanto, parece gerar ainda mais curiosidade. Conforme se sabe, é na adolescência que o sujeito busca experimentar novas sensações, enfrentar novos desafios e testar seus próprios limites. Desse modo, eles se aproximam do crack e nele veem uma forma de confrontar o que lhes é imposto socialmente e de se contrapor ao que lhes colocam como regra.

Como observado, a imagem do jovem bem vestido, higienizado e de boa aparência contrasta com a imagem exposta pela mídia sobre o usuário de crack, o qual, na maioria das vezes, é caracterizado por sua aparência descuidada, diante de um contexto de violência. Esta imagem traz uma percepção direta do que eles experimentam no seu cotidiano, alguém semelhante a qualquer outra pessoa, que vive, goza da sua saúde física, e que usa a droga sem maiores complicações sociais. Tal imagem contrasta com aquela exibida na mídia de massa.

\section{Padrões de consumo e estigmatização}

Em corroboração a essa representação simbólica, surgiu o discurso de que é possível o usuário utilizar o crack e manter suas relações laborais de maneira equilibrada, sem apresentar um comportamento violento e desorganizado, como se costuma ver na mídia de forma generalizada ${ }^{13}$.

Eu já tive um aluno há uns sete anos, funcionário da Mc Donald's, que usava drogas pesadas e era um aluno tranquilo em sala, agora não tinha um bom aprendizado, mas era tranquilo, não mexia com ninguém. Outra professora falou: olha, ele é usuário de crack, como é que pode? Ele trabalha e tudo e é um aluno que não é violento. (Professor 4)

Portanto, torna-se relevante discutir que nem todas as pessoas que usam determinada droga sofrem com os propalados prejuízos negativos por ela ocasionados e nem todas se tornam dependentes do crack. De acordo com Acserald ${ }^{14}$, para ocorrer o uso problemático, o conjunto de alguns fatores precisa ser levado em consideração, como a personalidade de quem usa, a droga escolhida, o meio e o momento em que se vive.

Em contrapartida, segundo identificado, relatos quanto ao uso desorganizado do crack constaram dos discursos, envolvendo pessoas do próprio convívio, isto é, tios, vizinhos ou amigos.

Meu tio [usuário]. Ele diz que é para eu ficar longe disso, que é para eu procurar o estudo, que isso daí é uma coisa que não tem cura. Que a cura para ele é a morte, porque ele não consegue parar. (Adolescente 2) Eu tenho um tio que é viciado, faz muita pena porque ele é bem sequinho, sequinho em vida. Eu sou assim, porque eu sou doente, sabe? Mas ele é assim porque fuma drogas. Acaba com as coisas da minha vó, ai quem sofre é ela, né?! (Adolescente 6)

A aproximação dos participantes com o crack promove visível inquietação, em especial por estarem expostos às drogas em seu ambiente social e familiar. Logo, como se identifica, a percepção do uso de crack é construída sobretudo, mediante experiências com a própria família ou pessoas do mesmo bairro.

\section{Essa questão da droga é complicada no sentido de que é muito acessi- vel para eles. Nossos alunos sofrem muito com essa questão. Acho que boa parte deles está em contato di- reto ou indireto, como usuário ou não. Pode perguntar, eles conhecem alguém que usa ou têm alguém na família que comercializa. Está muito próximo. A gente vê esse pro- cesso muito forte dentro dessas co- munidades. (Professor 5)}

Quanto às compreensões sobre o fenômeno crack na adolescência, enfatizam-se as seguintes falas, as quais têm associação com a dependência (vício) e o aborto.

Porque quer fumar direto e não
quer parar. (Adolescente 1)
É um perigo, porque aborta crian-
ça. (Adolescente 4)
Eu acho meio desesperador em com-
paração com as outras drogas. Eu
tenho amigos que são usuários de
maconha, de cocaina, mas que le-
vam a vida praticamente normal.
Tem seus empregos, mas eu sei que
usam. Eu não conheço nenhum
usuário de crack que tenha essa re-
lação. (Professor 3)

Ao se associar o uso de crack ao aborto, implicitamente se promove a reflexão segundo a qual o uso dessa droga não é uma prática apenas do gênero masculino e as mulheres que fazem uso abusivo no período gestacional podem sofrer repercussóes negativas nesse prisma.

De modo geral, as interpretações em torno dos discursos trazem marcante associação com os danos ocasionados pelo crack quando utilizado de forma abusiva. Assim, deixam de considerar os outros padrões de consumo, isto é, o experimental e o ocasional, padrões estes que, segundo a fala de um professor, não são 
possíveis quando se faz a opção pelo uso do crack.

Os participantes da pesquisa expressaram opiniões mais gerais em relação ao usuário de crack. Estas podem estar ancoradas em vivências com os usuários que enfrentam problemas decorrentes do consumo desorganizado desta droga ou em tendência da mídia e acabam reproduzindo as informações semelhantes àquelas exibidas nos programas policiais e, assim, deixam de promover uma reflexão mais profunda quanto a essa temática.

De acordo com Acserald ${ }^{14}$, quando se utiliza qualquer substância de modo problemático, consequentemente, ocorrem prejuízos ao organismo. No entanto, nem sempre os efeitos do crack se manifestam da mesma forma em todos os usuários, pois as sensações podem variar de pessoa a pessoa quando se considera o contexto de quem usa, ou seja, as dimensões física, psicológica e social.

Como mostram os discursos, a forma de perceber o aluno usuário de drogas ou de crack é pautada, por um lado, na visão estereotipada de que altera o modo de olhar, de se comportar, modifica a concentração, a forma de falar. Por outro lado, é preciso compreender que essas alterações, por si só, não justificam a associação com o uso de crack, mas abrem espaço para uma reflexão mais profunda sobre o contexto onde esse aluno está inserido.

Com base nessas interpretações, urge refletir sobre o seguinte: esta percepção deve ser estimulada por meio de um acompanhamento atento e cuidadoso aos alunos, pois outras situações associadas a problemas emocionais, transformações em virtude do próprio período da adolescência, com alterações hormonais e de humor, carências nutricionais, possíveis transtornos como déficit de atenção ou até mesmo na depressão, podem ser responsáveis por mudanças de ordem emocional ou biológica.

$\mathrm{O}$ início do uso de crack na adolescência foi outro ponto discutido entre os participantes. Conforme evidenciado, os discursos estão atrelados ao convite dos amigos e à reprodução do comportamento voltado para o uso de crack, mediante in- fluência de pessoas de sua comunidade ou dos próprios familiares.

Tem a família que usa e a criança vê e tenta pegar. Ah, está dentro de casa, ai acaba enrolando um também, aí para sair que é difícil?! (Adolescente 4)

Mas eu acredito que o que mais influencia são os pais usuários ou até mesmo os pais ausentes. Que aí o que vai educá-los vai ser a rua e às vezes o entorno onde eles vivem tem a droga e eles acabam sendo influenciados pelo entorno onde eles vivem né? Com certeza, fica bem mais fácil o acesso. (Professor 2)

Em corroboração a esse estudo, resultados semelhantes foram encontrados no estudo de Faria Filho ${ }^{15}$ et al. quanto às concepções de adolescentes sobre drogas. De acordo com os autores, os significados que os adolescentes constroem em relação à droga possivelmente podem estar associados a reproduções históricas e socialmente construídas, ao ouvirem relatos de pessoas do próprio convívio ou da mídia. Assim reproduzem um conceito estabelecido socialmente, e, desse modo, não conseguem elaborar reflexões mais profundas sobre $\mathrm{o}$ assunto.

Segundo se compreende, a percepção em volta do adolescente usuário deve ser construída com um olhar sensível aos reais problemas potenciais que podem surgir nessa fase da vida. Portanto, é preciso atentar para outras possibilidades de sofrimento das quais podem ser vítimas como alterações na autoestima, nas relações sociais e familiares que nem sempre estão atreladas ao uso problemático do crack.

As representações sobre o sofrimento em decorrência do uso, a necessidade de praticar roubos, de vender objetos de casa ou a relação com o tráfico se fizeram presentes nas falas dos alunos e denotam as consequências da desorganização do uso do crack, culminando com uma desestruturação complexa por parte do usuário.

A partir disso, pode haver um sofrimento instalado socialmente para aqueles desprovidos da mínima assistência pelas políticas públicas quanto ao uso problemático de drogas. Ademais, os jovens, nem sempre usuários de drogas, convivem com pessoas em situação de adoecimento e, consequentemente, também podem sofrer com esse processo.

Consoante constatado por alguns autores ${ }^{16}$, em seu estudo sobre a adolescência e os fatores biopsicossociais relacionados ao uso de drogas entre os 229 adolescentes pesquisados, muitos afirmaram conviver com familiares que utilizavam algum tipo de droga $(56,8 \%)$, e que esse fato trouxe repercussões negativas na vida escolar desses jovens.

Reflete-se na perspectiva segundo a qual não é o adolescente que absorve o crack, mas o crack é que acaba absorvendo as significações construídas socialmente, sejam positivas, sejam negativas. Para determinados adolescentes o uso perigoso desta droga é devido a vários exemplos vivenciados nas suas realidades sociais. Pessoas se desorganizando por causa do uso, brigando, vivendo em conflitos de diversas ordens.

Cabe ressaltar: de modo geral, os jovens da classe social média e alta têm acesso a atividades de lazer, a uma escola que promove orientações sobre o uso de drogas e que acompanha de perto as atividades educativas; eles têm condições de viajar, praticar esportes, têm acesso a uma saúde de qualidade e uma família estruturada. Evidencia-se, então, o quanto se vive em uma sociedade desigual, uma vez que os jovens de classes menos favorecidas vivem em situação de pobreza sem condições de acessar as atividades de lazer, educação e saúde de qualidade. Vivem à margem da sociedade e sentem a necessidade de se afirmarem em seu próprio contexto.

Em virtude dessa desigualdade social é a droga que promove o acesso a esses bens de consumo e garante o status tão desejado por muitos adolescentes. Dessa forma, o crack acaba sendo interpretado como o meio de socialização e de reafirmação em seu contexto cultural. Em contrapartida, o uso dessa droga pode ser negado em decorrência de todo o preconceito criado em torno do usuário. É mais fácil assumir o consumo de bebida alcoólica ou maco- 
nha, que são substâncias mais aceitas socialmente, pois na visão dos estudantes e professores, o crack é uma droga pesada e geradora de profundas repercussóes na vida dos adolescentes.

Eles não têm essa noção não. Pelo fato de a comunidade ser inserida num contexto social bem complexo, onde as drogas permeiam todas as nuances sociais deles, eles encaram como uma coisa normal. Eu vejo isso, a droga é normal. Eu já ouvi: fulano é avião, professor. (Professor 4) Eles acham legal [...]. É status, éimportante. É normal. O natural para eles é usar e na maioria das vezes, encobrir que usa. (Professor 5)

Essa realidade abre margem a uma maior reflexão quanto à necessidade intrínseca das pessoas de se relacionarem umas com as outras, pois se somos seres sociais, precisamos de instrumentos que possibilitem sociabilidade. Se os jovens sentirem falta de instrumentos favoráveis a essa comunhão social, consequentemente, eles encontrarão o que está disponível socialmente, como por exemplo, o crack.

$\mathrm{O}$ meio e o contexto onde os adolescentes vivem também exercem influência sobre suas escolhas e comportamentos. Assim, a acessibilidade à droga pode ser fácil e eles podem achar natural essa relação com o crack, já que reproduzem esse tipo de comportamento, o qual, muitas vezes, é vivenciando dentro da própria casa.

\section{CONCLUSÃO}

Conforme o estudo demonstrou, há mais facilidade em compreender o crack como objeto causador de desfechos negativos, entre estes, a violência, a morte e a reclusão social, com argumentações superficiais e simplórias, ancoradas em estigmas e preconceitos. Apesar disso, na adolescência o crack é tido como elemento de comunhão social, como um desafio e como objeto de afirmação em seu grupo de amigos. Desse modo, requer mais atenção já que os jovens são mais vulneráveis às drogas.

É preciso estimular a elaboração de estratégias de promoção à saúde do adolescente, que diminuam as barreiras do preconceito, e assim, facilitem a comunicação aberta sobre a problemática do uso de crack. Cabe considerar sobretudo os moradores de comunidades mais carentes, porquanto tendem a vivenciar, direta ou indiretamente, experiências com as drogas. Diante disso, silenciar quanto a este assunto é privar esta população de informações relevantes para uma possível tomada de decisão consciente. -

\section{REFERÊNCIAS}

1. Medeiros DG, Faria PH, Campos GWS, Tófoli LF. Política de drogas e Saúde Coletiva: diálogos necessários. Cad. Saúde Pública, 2019; 35(7).

2. Paula ML, Jorge MSB, Lima LL, Bezerra IC. Experiências de adolescentes em uso de crack e seus familiares com a atenção psicossocial e institucionalização. Ciência \& Saúde Coletiva, 2017 22(8):2735-2744.

3. Zeitoune RCG, Ferreira VS, Silveira HS, Domingos AM, Maia A. 0 conhecimento de adolescentes sobre drogas. Esc Anna Nery (São Paulo). 2012; 16 (1):57- 63.

4. Paula ML, Jorge MSB, Vasconcelos MGFV. Revista de Saúde Coletiva, Rio de Janeiro, 2019, v. 29(1).

5. Costa AG, Camurça, VV, Braga JM, Tatmatsu, DIB. Drogas em áreas de risco: o que dizem os jovens. Physis (Rio de Janeiro). 2012, 2(22):803-19.

6. VI Levantamento Nacional sobre o Consumo de Drogas Psicotrópicas entre Estudantes do Ensino Fundamental e Médio das Redes Pública e Privada de Ensino nas 27 Capitais Brasileiras - 2010/ Carlini EA, Noto AR, Sanchez ZM. (supervisão), -- São Paulo: CEBRID - Centro Brasileiro de Informações sobre Drogas Psicotrópicas: UNIFESP - Universidade Federal de São Paulo 2010. SENAD - Secretaria Nacional de Políticas sobre Drogas, Brasília - SENAD, 2010. 503 p.

7. Ipece. 0 Uso de Drogas Ilícitas entre Estudantes do Ensino Fundamental em Fortaleza e demais Capitais Brasileiras - 2012. R. S. Sales (elaboração) [et al.], -- Fortaleza: Informe, nº 72, 2014.
8. Thiollent M. Metodologia da pesquisa-ação. Brasilia: Cortez, 2011.

9. Terra, MG, Gonçalves LHT, Santos EKA, Erdmann AL. Fenomenologia-hermenêutica de Paul Ricoeur como referencial metodológico numa pesquisa de ensino em enfermagem. Acta paul. enferm., São Paulo, v. 22, n. 1, p.93-99, fev, 2009.

10. Goldberg LG, Yunes MM, Freitas JV. O desenho infantil na ótica da ecologia do desenvolvimento humano. Psicologia em Estudo. 2005,10 (1) 97-106.

11. Araújo CCM, Lacerda CBF. Examinando o desenho infantil como recurso terapêutico para o desenvolvimento de linguagem de crianças surdas. Revista da Sociedade Brasileira de Fonoaudiologia. 2008,13(2) 186-12.

12. Quinderé PHD. A experiência do uso de crack e sua interlocução com a clínica: dispositivos para o cuidado integral do usuário [tese]. Fortaleza (CE): Universidade Estadual do Ceará; 2013.

13. Bard ND, Antunes B, Roos CM, Olschowsky A, Pinho LB. Estigma e preconceito: vivência dos usuários de crack. Rev. Latino-Am. Enfermagem [Internet]. 2016 [cited 2020 Dec 16]; 24.

14. Acserald G. Quem tem medo de falar sobre drogas? Saber mais para se proteger. Rio de Janeiro: Editora FGV; 2015.

15. Faria Filho EA, Queiros PS, Medeiros M, Rosso CF, Weirich SM. Concepções sobre drogas por adolescentes escolares. Revista Brasileira de Enfermagem. (Brasília). 2015; 3(68):517-23.

16. Bittencourt ALP, França LG, Goldim JR. Adolescência vulnerável: fatores biopsicossociais relacionados ao uso de drogas. Rev. Bioética (São Paulo). 2015; 2(23):311-19. 